Este documento ha sido publicado en:

Quispe Remón, Florabel (2016). La protección de los derechos humanos en el sistema interamericano: su evolución y una visión actual. Anuario Español de Derecho Internacional, 32, pp. 225 - 258. DOI: 10.15581/010.32.225-258

(C) Servicio de Publicaciones, Universidad de Navarra, 2016

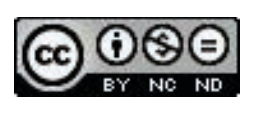

Licencia Creative Commons Reconocimiento-NoComercialSinObraDerivada 3.0 España. 


\title{
La protección de los derechos humanos en el sistema interamericano: su evolución y una visión actual*
}

\author{
The protection of human rights in the inter-American system: \\ evolution and current vision
}

\author{
Florabel QUISPE REMÓN \\ Titular acreditada de Derecho Internacional Público \\ Universidad Carlos III de Madrid \\ fquispe@der-pu.uczm.es
}

Resumen: El presente trabajo analiza desde un punto de vista histórico-jurídico el desarrollo del sistema interamericano de protección de los derechos humanos desde su origen en 1948 hasta la actualidad a través de sus órganos de protección, especialmente el de la Corte Interamericana de Derecho Humanos. Visibiliza los avances tanto en los aspectos sustantivos como procesales. Asimismo, identifica debilidades del sistema y posibles soluciones, para una mayor y mejor protección de las personas de esta región.

Palabras clave: Derechos humanos, sistema interamericano, corte interamericana, sentencias, opiniones consultivas, avances y debilidades.

\begin{abstract}
This paper analyzes from a historical point of view-legal development of the inter-American system for the protection of human rights since its inception in 1948 to the present through their protection bodies, especially the Inter-American Court of Human Rights. Makes visible progress in both substantive and procedural aspects. It also establishes the possible weaknesses in the system and possible solutions for greater and better protection of the people of this region.
\end{abstract}

Keywords: Human rights, inter-American system, interAmerican court, judgments, advisory opinions, progress and weaknesses.

Sumario: I. INTRODUCCIÓN. II. ANTECEDENTES Y PRINCIPALES INSTRUMENTOS DEL SISTEMA INTERAMERICANO DE PROTECCIÓN DE LOS DERECHOS HUMANOS. III. LAS SENTENCIAS Y OPINIONES CONSULTIVAS DE LA CORTE INTERAMERICANA COMO MECANISMOS DE AMPLIACIÓN DEL CATÁLOGO DE LOS DERECHOS RECONOCIDOS EN LA CONVENCIÓN AMERICANA. 1. Las opiniones consultivas: un mecanismo de aporte en la protección de derechos: a. Sobre el valor jurídico de la Declaración Americana. b. Ampliación de las excepciones al agotamiento de los recursos internos. 2. El aporte de la Corte Interamericana a través de sus sentencias: a. Adopción de decisiones sin precedentes. b. La incorporación de control de convencionalidad en el Sistema. c. El desarrollo del debido proceso y las opiniones consultivas. d. Las reparaciones y su desarrollo a la luz de la jurisprudencia. e. La nueva concepción del juez ad hoc en el sistema interamericano. IV. MEDIDAS DE ACCESO A LA JUSTICIA INTERNACIONAL AMERICANA: UN AVANCE EN LA PROTECCIÓN DE LOS DERECHOS HUMANOS. 1. El establecimiento del Fondo de Asistencia Legal. 2. La creación del Defensor Interamericano. V. POSIBLES DEBILIDADES DEL SISTEMA: ASPECTOS A REFORZAR. 1. Los Estados y el cumplimiento de sentencias. 2. La supervisión del cumplimiento de las sentencias de la Corte Interamericana: un aspecto clave en la efectividad del Sistema 3. La creación de una Corte Permanente y el fortalecimiento del Sistema interamericano. 4. Las denuncias de los Estados a la CADH y el debilitamiento del Sistema. VI. REFLEXIONES FINALES.

* El presente trabajó se elabora en el marco del Proyecto I+D «Actores económicos internacionales y derechos humanos. Especial relevancia para España». Referencia DER 2014-55484-P. 


\section{INTRODUCCIÓN}

$\mathrm{D}$ esde mediados del siglo XX en la comunidad internacional se inicia la preocupación por el reconocimiento internacional de derechos a las personas, por el respeto a su dignidad, a la libertad, a la seguridad e igualdad entre hombres y mujeres. Hasta entonces los derechos de las personas constituían una competencia exclusiva del Estado. Por ello, el origen de la humanización del derecho internacional, se sitúa, en fechas posteriores a la Segunda Guerra Mundial. Es así que los derechos humanos como se conocen hoy es un concepto propio del Derecho internacional contemporáneo.

En el continente americano existe hoy por hoy un sistema de protección de los derechos humanos que se viene construyendo desde 1948, año en el que por vez primera en el mundo se adopta un instrumento regional, no vinculante, que reconoce derechos humanos, denominado Declaración Americana de los Derechos y Deberes del Hombre (la Declaración o DADH)․․ En estos sesenta y ocho años el sistema interamericano ha venido desarrollándose paulatinamente teniendo en cuenta la evolución del tiempo y los cambios de la $\operatorname{sociedad}^{2}$. Este avance se ha venido llevando a cabo a través de la adopción

1 Aunque los precedentes se remontan al siglo XIX. El presidente de los EE.UU. en 1888 convocó a las repúblicas latinoamericanas a un Primera Conferencia Internacional en Washington que se celebró entre el 2 de octubre y el 14 de abril de 1890. Ésta concluye con la creación de la Unión Internacional de las Repúblicas Americanas, cuyo apoyo era la Oficina Comercial de las Repúblicas Americanas con sede en Washington-predecesora de la OEA. Desde 1890 hasta 1948 se celebraron nueve conferencias panamericanas ordinarias y cuatro extraordinarias: la Conferencia de Washington (1890); la de México (1901), la de Río de Janeiro (1906), la de Buenos Aires (1910), la de Santiago de Chile (1923), la de La Habana (1928), la de Montevideo (1933), la de Lima (1938) y la novena en Bogotá (1948) donde se elaboró la Carta de la OEA. De las extraordinarias hay que destacar la Conferencia de Chapultepec (1945) por cuanto marca un hito en la historia de los derechos humanos en el continente americano ya que se adoptan medidas, por vez primera, medidas de la política continental en el campo de los derechos humanos. Se adoptaron dos resoluciones importantes: La Resol. XXVII sobre Libertad de Información y la Resol. XL sobre Protección Internacional de los Derechos Esenciales del Hombre, predecesora de la DADH. Cfr. Documentos básicos en materia de derechos humanos en el Sistema Interamericano. Organización de los Estados Americanos, Comisión Interamericana de Derechos Humanos, Washington, enero 2004, pp. 3-15, y Documentos básicos en materia de derechos humanos en el Sistema Interamericano, Organización de los Estados Americanos, Corte Interamericana de Derechos Humanos, San José, Costa Rica, 2003, p. 5-17.

2 Varios de los Estados de esta región durante este periodo han sufrido dictaduras cuyas consecuencias, entre otras, han sido la vulneración de los derechos humanos. En algunos casos, tales como, Almonacid Arellano c. Chile o Gelman c. Uruguay, la Corte Interamericana ha tenido ocasión de pronunciarse. 
de instrumentos que reconocen derechos civiles y políticos, así como los derechos económicos, sociales y culturales (DESC). A ello se suma otros instrumentos de carácter temático cuyo fin es proteger a los grupos vulnerables. En este desarrollo han jugado un papel importante los órganos de protección de los derechos humanos en el Sistema Interamericano, esto es, la Comisión y la Corte Interamericana de Derechos Humanos a través de sus opiniones y sus decisiones.

El presente trabajo pretende, por un lado mostrar brevemente los avances a nivel sustantivo y procesal del sistema en la protección del ser humano; el papel de la Corte Interamericana a través de la interpretación que ha venido realizando de la Convención Americana de Derechos Humanos y otros instrumentos en sus treinta y ocho años de funcionamiento; y por otro visualizar los posibles aspectos que debilitan el sistema y sobre los que se deben tomar medidas a fin de fortalecer y brindar una mejor protección al ser humano que se encuentra en dicha región.

Realizaremos un estudio histórico jurídico que nos permitirá tener una visión completa del statu quo de este Sistema. Para ello, acudiremos a los instrumentos básicos del sistema interamericano, a los reglamentos de la Corte y de la Comisión Interamericana, a las sentencias y opiniones consultivas además de las fuentes doctrinales, para finalizar con unas reflexiones.

\section{ANTECEDENTES Y PRINCIPALES INSTRUMENTOS DEL SiSTEMA INTERAMERICANO DE PROTECCIÓN DE LOS DERECHOS HUMANOS}

Los Estados del continente americano reconocen los derechos humanos casi de forma paralela a los Estados en el ámbito universal, a mediados del siglo Xx. Es más, el primer instrumento en el que se reconocen y determinan los derechos humanos, es la Declaración Americana de Derechos y Deberes del Hombre aprobada en junio de 1948, meses antes a la Declaración Universal de los Derechos Humanos de diciembre de 1948. Se trata de un instrumento que nace sin fuerza jurídica y, por ende, no establece un órgano encargado de supervisar su cumplimiento. No obstante hay que señalar, sin duda alguna, que se trata de la primera piedra en la protección de los derechos humanos $(\mathrm{DDHH})$ en la región sobre la que se construye el Sistema Interamericano de los Derechos Humanos (SIDH).

$\mathrm{La} \mathrm{DADH}$ en su parte introductoria deja claramente establecido que la protección de los derechos del hombre debe ser, en el derecho americano en 
evolución, su guía principal y, debe ser fortalecido cada vez más en el ámbito internacional. Expresa que los derechos básicos del hombre no nacen del hecho de ser nacional de un Estado sino que tiene como fundamento los atributos de la persona humana.

Desde entonces bajo el paraguas de la Organización de los Estados Americanos $(\mathrm{OEA})^{3}$, que tenía como uno de sus principios, que regiría su funcionamiento, el reconocimiento y protección de los derechos humanos, se ha venido desarrollado el SIDH. Durante este más de medio siglo de existencia hemos visto avances y dificultades en su desarrollo. En este contexto en 1959 la OEA crea la Comisión Interamericana de Derechos Humanos (La Comisión o CIDH) como un órgano encargado de promover y proteger los derechos humanos en dicha organización, además de ser su órgano consultor. Más tarde la Comisión también es recogida en la Convención Americana de Derechos Humanos como un órgano del Sistema Interamericano de Protección de los derechos humanos.

El 22 de noviembre de 1969 se adopta el primer instrumento vinculante en materia de derechos humanos en la región, la Convención Americana de Derechos Humanos (CADH) que entró en vigor el 18 de julio de 1978. Un instrumento que por un lado, recoge un catálogo de derechos de las personas, crea los órganos encargados de proteger tales derechos, la Comisión y la Corte Interamericana de Derechos Humanos (CIDH) y por otro, establece obligaciones para los Estados. En definitiva se trata de un instrumento que hace titulares de los derechos a los seres humanos y establece obligaciones para los Estados. Asimismo este instrumento reconoce el derecho a la reserva, a las enmiendas, a los protocolos y a las denuncias a la $\mathrm{CADH}$ por parte de los Estados. En este contexto, se han adoptado dos protocolos a la $\mathrm{CADH}$, el Protocolo de San Salvador de 1988 que reconoce Derechos Económicos, Sociales y Culturales y el Protocolo de Asunción de 1990 sobre la Abolición de la Pena de Muerte. Más tarde en el seno del sistema se han adoptado otros instrumentos de carácter temático teniendo en cuenta el avance del tiempo, el desarrollo y la necesidad de la sociedad a fin de brindar una mayor y mejor protección a los grupos vulnerables ${ }^{4}$.

3 No obstante es de señalar que desde 1890 los Estados de esta región del mundo ya se encontraban agrupados en la Unión Panamericana, pero su prioridad no eran los derechos humanos ni en su seno se adoptó ningún instrumento que reconociera derechos civiles y políticos.

4 Convención Interamericana para Prevenir y Sancionar la tortura, 12 de septiembre de 1985; Convención Interamericana sobre Desaparición Forzada de Personas, 9 de junio de 1994; Con- 
Hoy en día son treinta y cinco Estados los que forman parte de la OEA de los cuales solo veintitrés han ratificado la Convención Americana de Derechos Humanos ${ }^{6} \mathrm{y}$ veinte han asumido la competencia contenciosa de la Corte. Lo que significa que solo veintitrés Estados se obligan a reconocer y proteger los derechos humanos recogidos en la Convención Americana y solo veinte aceptan la competencia contenciosa de la Corte Interamericana, es decir, la Corte solo puede conocer de presuntas violaciones a los derechos humanos cometidos por estos veinte Estados que voluntariamente aceptaron dicha competencia ${ }^{7}$. Dentro de estos no está Estados Unidos y por ende, la Corte, por ejemplo, no podría pronunciarse sobre la violación de los derechos humanos en Guantánamo.

\section{LAS SENTENCIAS Y OPINIONES CONSULTIVAS DE LA CORTE INTERAMERICANA COMO MECANISMOS DE AMPLIACIÓN DEL CATÁLOGO DE LOS DERECHOS RECONOCIDOS EN LA CONVENCIÓN AMERICANA}

La Corte interamericana, una institución judicial autónoma del sistema interamericano cuyo objetivo es la aplicación e interpretación de la $\mathrm{CADH}$, desempeña sus funciones conforme a este tratado principal del sistema. Es el

vención Interamericana para prevenir, sancionar y erradicar la violencia contra la mujer (Belem do Pará) 9 de junio de 1994; Convención Interamericana contra la Corrupción, 29 de marzo de 1996; Convención Interamericana para la Eliminación de todas las Formas de Discriminación contra las Personas con Discapacidad, 6 de julio de 1999; Convención Interamericana contra el Racismo, la Discriminación racial y Formas Conexas de intolerancia, 6 de mayo de 2013; Convención Interamericana contra Toda Forma de Discriminación e Intolerancia, 5 de junio de 2013; Convención Interamericana sobre la Protección de los Derechos Humanos de las Personas Mayores, 15 de junio de 2015.

5 En el Sistema Europeo los cuarenta y siete Estados que forman parte del Consejo de Europa han ratificado el Convenio Europeo de Derechos Humanos. Forman parte del Sistema prácticamente todos los Estados de Europa menos Bielorrusia y Kazajistán. La Ciudad del Vaticano tiene el Estatus de Estado observador, además de otros no europeos como Canadá, Japón, México, Israel, Estados Unidos. Los nuevos Estados reconocidos como Kosovo, Osetia del Sur forman parte del Sistema.

6 Argentina, Barbados, Bolivia, Brasil, Chile, Colombia, Costa Rica, Dominica Ecuador, El Salvador, Guatemala, Grenada, Haití, Honduras, Jamaica, México, Nicaragua, Panamá, Paraguay, Perú, República Dominicana, Suriname y Uruguay

7 Argentina, Barbados, Bolivia, Brasil, Chile, Colombia, Costa Rica, Ecuador, El Salvador, Guatemala, Haití, Honduras, México, Nicaragua, Panamá, Paraguay, Perú, República Dominicana, Suriname y Uruguay. A diferencia del Sistema Interamericano en el Sistema Europeo todos los Estados que han ratificado la Convención Europea de Derechos Humanos también han asumido la competencia contenciosa del Tribunal Europeo (47 Estados). 
máximo intérprete de la Convención. Sus decisiones son definitivas e inapelables $^{8}$. Su procedimiento y organización se rige conforme a su Estatuto y su Reglamento que ha sido modificado hasta en seis ocasiones. La vigente es del 24 de noviembre del $2009^{10}$.

La Corte comenzó a funcionar en septiembre de 1979 y ejerce doble competencia: contenciosa recogida en los arts. 61, 62 y 63 y consultiva establecida en el art. 64 de la CADH, a ello se suma la potestad de dictar medidas provisionales conforme al punto dos del art. 63. Su primera sentencia la emitió en el caso Velásquez Rodríguez contra Honduras una década más tarde del el inicio de sus labores, en 1989. Desde entonces ha adoptado más de un centenar de sentencias ${ }^{11}$, veintiuna opiniones consultivas a petición de los Estados en algunos casos y en otros a petición de la Comisión Interamericana de Derechos Humanos. Ha decidido en muchas ocasiones, cuando lo consideró necesario, adoptar medidas provisionales en casos de extrema gravedad y urgencia a fin de evitar daños irreparables a las personas ${ }^{12}$.

Sus sentencias sin duda han sido innovadoras, progresistas y valientes. Ha tomado decisiones de gran trascendencia en aras de ofrecer una mejor protección a los seres humanos que viven en dicha región haciendo una amplía interpretación de los artículos que reconocen derechos en la CADH. Para la Corte los tratados de derechos humanos son instrumentos vivos y su interpretación debe acompañar a la evolución de los tiempos y las condiciones de vida actua-

8 Sus decisiones se notifican a las partes y a los demás Estados miembros. En caso de desacuerdo sobre el alcance de la sentencia se puede pedir la interpretación de la misma ante el mismo órgano en un plazo de noventa días desde la notificación con la sentencia.

9 Aprobado mediante Resolución n 448 adoptada por la Asamblea General de la OEA en su noveno período de sesiones, celebrado en La Paz, Bolivia, octubre de 1979.

10 Los Reglamentos aprobados en 1980, 1991, 1996, 2000, 2003, 2006, 2009. El último entró en vigor el 1 de enero del 2010. Véase los reglamentos completos <www.corteidh.or.cr/index.php/ es/acerca-de/reglamento/reglamentos-anteriores> [última visita: 01-2016].

11 Conforme al Informe Anual 2014 de la Corte Interamericana, ésta ha resuelto 216 y tiene pendiente de resolver 71 casos. Véase: <www.corteidh.or.cr/sitios/informes/docs/SPA/spa_2014. pdf>, pp.69-71.

12 Cuenta con 29 medidas provisiones bajo supervisión. Cfr. Informe Anual 2014, pp. 72. Toda la información sobre las medidas provisionales adoptadas hasta 2014 pueden verse en: Sistematización de las Resoluciones sobre Medidas Provisionales emitidas por la Corte Interamericana de Derechos Humanos (arts. 63.2 de la Convención Americana de Derechos Humanos y 27 del Reglamento de la Corte Interamericana). La Corte para la realización de la sistematización toma en cuenta tres criterios: Por personas beneficiarias protegidas por las medidas provisionales y derecho protegido; por el momento procesal en que es solicitado a la Corte que adopte medidas provisionales y por el estado de vigencia o levantamiento de las medidas provisionales. En <www.corteidh.or.cr/sitios/libros/todos/ docs/Sistematizacion.pdf> [última visita: 01-2016]. 
les ${ }^{13}$. En ese sentido sus sentencias siempre han sido pro homini. Justamente a través de esta interpretación progresista realizada a través de las competencias ha venido ampliando el catálogo de los derechos reconocidos en la $\mathrm{CADH}$.

\section{Las opiniones consultivas: un mecanismo de aporte en la protección de derechos}

a) Sobre el valor jurídico de la Declaración Americana

Las opiniones consultivas han sido ampliamente utilizadas en este sistema a diferencia de los otros sistemas regionales. A través de éstas ha realizado interpretaciones importantes, que dada la extensión del trabajo no se puede hacer referencia a todas, pero sí a algunas de ellas como la OC-10/89 en la que se pronunció sobre el valor jurídico de la Declaración Americana en el marco legal del sistema interamericano de protección de los derechos humanos a petición del gobierno colombiano ${ }^{14}$. Esta Declaración al igual que la Declaración Universal de derechos humanos nace con un gran valor moral y político pero no jurídico. La Corte deja claro que su competencia conforme al art. 64 de la $\mathrm{CADH}$ es para interpretar tratados, y la Declaración no es un tratado, pero que esta afirmación por sí sola no lleva necesariamente a la conclusión de la inadmisibilidad de la solicitud, y procede a emitir su opinión sobre la consulta ${ }^{15}$. La Corte reconoce que «para los Estados Miembros de la Organización, la Declaración es el texto que determina cuáles son los derechos humanos a que se refiere la Carta (...). Es decir para estos Estados la Declaración Americana constituye, en lo pertinente y en relación con la Carta de la Organización una fuente de obligaciones internacionales. Si bien en principio para los Estados partes la fuente concreta de su obligación respecto a los DDHH es la Convención, se debe tener en cuenta que ninguna disposición de la Convención puede ser interpretada excluyendo o limitando el efecto que pueda producir la $\mathrm{DADH}$ y otros actos internacionales de la misma naturaleza tal y como lo señala el art. 29.d de la CADH. Así en palabras de este órgano judicial, esto no

13 Corte Interamericana de Derechos Humanos, Opinión Consultiva 16/99, de 1 de octubre de 1999, solicitada por los Estados Unidos Mexicanos, p. 114.

14 Corte Interamericana de Derechos Humanos, Opinión consultiva 10/89 de 14 de julio de 1989, solicitada por el gobierno de Colombia. Interpretación de la Declaración Americana de los Derechos y Deberes del Hombre en el marco del artículo 64 de la Convención Americana sobre Derechos Humanos.

15 Idem, párr.23. 
libera a los Estados de las obligaciones que derivan para ellos de la Declaración por el hecho de ser miembro de la $\mathrm{OEA}^{16}$. Concluye señalando:

«La circunstancia de que la Declaración no sea un tratado no lleva, entonces, a la conclusión de que carezca de efecto jurídico ni a la de que la Corte esté imposibilitada para interpretarla en el marco de lo precedentemente expuesto» ${ }^{17}$.

Así se pronuncia sobre la obligatoriedad de ésta, que constituyó la primera piedra en la construcción de lo que hoy conocemos como Sistema Interamericano, para todos los Estados miembros de la $\mathrm{OEA}^{18}$. Obliga a todos los Estados Miembros de la OEA a su cumplimiento. Siendo ello así, la Comisión Interamericana si puede pronunciarse sobre el respeto de los derechos recogidos en la Declaración respecto de cualquier Estado Miembro de la OEA. Así lo hizo al pronunciarse contra Estados Unidos sobre el caso Guantánamo.

b) Ampliación de las excepciones al agotamiento de los recursos internos

Otra opinión consultiva a destacar es la OC-11/90 planteada por la Comisión Interamericana sobre las excepciones al agotamiento de los recursos internos. La Comisión señala que si bien el artículo 46.2 de la CADH hace referencia a las excepciones pero no hace referencia específica a los indigentes ni a las situaciones en las cuales una persona no ha podido obtener representación legal dada la existencia de un temor generalizado de los abogados para dársela. Respecto a la indigencia, la Corte deja dicho que si un individuo requiere efectivamente asistencia legal para proteger un derecho garantizado por la Convención y su indigencia le impide obtenerla, queda relevado de agotar los recursos internos. Este es el sentido que tiene el artículo 46.2, leído a la luz de las disposiciones de los artículos 1.1, 24 y $8{ }^{19}$. Igualmente deja dicho que si un reclamante ante la Comisión se ha visto impedido, por el temor generalizado de los abogados

\footnotetext{
Idem, párr. 45 y 46.

Idem, párr. 47.

18 Un estudio sobre el aporte de la Declaración Americana a la protección de los derechos humanos se puede encontrar en el trabajo de SALVIOLI, F., El aporte de la Declaración Americana de 1948 para la protección internacional de los derechos humanos. Cfr. <www.derechoshumanos.unlp.edu.ar> [última visita: 10-2015].

19 Corte Interamericana de Derechos Humanos, OC-11/90 del 10 de agosto de 1990, Excepciones al agotamiento de los recursos internos (art.46.1, 46.2.a y 46.2.b Convención Americana de Derechos Humanos) solicitada por la Comisión interamericana de Derechos Humanos, párr.31.
} 
para representarlo legalmente, de utilizar los recursos internos necesarios para proteger un derecho garantizado por la Convención, no se le puede exigir su agotamiento. De esta forma amplía de tres a cinco las excepciones al agotamiento de los recursos internos mencionados en la $\mathrm{CADH}$ incluyendo dos supuestos que son frecuentes en las realidades de la región. La primera dada la situación económica de gran parte de los países y la segunda dependiendo del contexto político social que atraviesa un país en un determinado momento.

\section{El aporte de la Corte Interamericana a través de sus sentencias}

Como ya mencionamos, la Corte comenzó a funcionar en los años sesenta y entonces varios países de la región atravesaban o estaban saliendo de dictaduras y esta situación hizo que este órgano ejerciendo su competencia contenciosa focalizara su atención durante estos primeros años en casos vinculados con la desaparición forzada de personas, las ejecuciones extrajudiciales y los tribunales militares.

Luego ha conocido y se ha pronunciado sobre diversos temas como el de género, los pueblos indígenas, el derecho de los niños, la fecundación in vitro, los migrantes, el derecho al debido proceso, la libertad de expresión, etc. También se ha pronunciado sobre las leyes de amnistía y las leyes de caducidad dejando claro que no son admisibles cuando se trata de la violación a los derechos humanos porque son incompatibles con la Convención Americana y carecen de efectos jurídicos ${ }^{20}$.

\section{a) Adopción de decisiones sin precedentes}

Ordenó al Estado peruano en un plazo razonable liberar a una persona que se encontraba cumpliendo condena en dicho país ${ }^{21}$. Además ordenó al Estado adoptar las medidas necesarias para asegurar que ninguna resolución adversa emitida en el proceso a que fue sometida la Sra. Loayza Tamayo ante el fuero civil produzca efecto legal ${ }^{22}$.

20 Entre otros véase: Corte Interamericana, Caso Barrios Altos $c$. Perú, Sentencia CIDH de 14 de marzo de 2001, Caso Gelman c. Uruguay, 24 de febrero de 2011.

21 Corte Interamericana de Derechos Humanos, Caso Loayza Tamayo c. Perú, sentencia de 17 de septiembre de 1997 (fondo), punto resolutivo 5.

22 Corte Interamericana de Derecho Humanos, Caso Loayza Tamayo c. Perú, Sentencia de 27 de noviembre de 1998 (Reparaciones y Costas), párr.192.3. 
En el caso Castillo Petruzzi declaró directamente la invalidez del proceso seguido en derecho interno por ser incompatible con la Convención Americana y ordenó un nuevo juicio observando el debido proceso. Asimismo ordenó al Estado tomar medidas para reformar aquellas normas declaradas por este órgano judicial violatorias de la Convención Americana ${ }^{23}$. Ante semejantes decisiones hay quien señaló, con razón, que «ninguna otra Corte internacional de derechos humanos, se había comprometido antes a ordenar, sin respaldo de órganos políticos, una indemnización tan potencialmente provocativa, particularmente si se toma en cuenta un contexto tan delicado políticamente y que se dictó frente a un régimen de línea tan dura como es el del Presidente peruano Alberto Fujimori ${ }^{24}$. Más tarde Fujimori planteo su retiro a la competencia de la Corte, afortunadamente, sin éxito.

Por otro lado, ha reconocido derechos colectivos a los Pueblos Indígenas al amparo del artículo 21 de la $\mathrm{CADH}$, no obstante a que este artículo al igual que otros tratados internacionales de protección de los derechos humanos en el resto del mundo, solo reconoce derechos de propiedad individuales ${ }^{25}$. Ha ordenado que el Estado chileno, en un plazo razonable, modifique su ordenamiento jurídico interno a fin de suprimir la censura previa y le otorga seis meses para que informe a la Corte sobre las medidas tomadas ${ }^{26}$. Ha declarado que la Ley de Caducidad uruguaya dada su incompatibilidad con la Convención Americana carece de efectos jurídicos, no obstante a haber sido refrendado por el pueblo uruguayo hasta en dos ocasiones por medio de referéndum y plebiscito ${ }^{27}$. Se he pronunciado a favor de la fecundación in vitro no obstante a que el Tribunal Constitucional de Costa Rica había declarado inconstitucional la norma que reconocía este tipo de reproducción asistida. Señaló que las autoridades pertinentes del Estado deben adoptar las medidas apropiadas, con la mayor celeridad posible, para que quede sin efecto la prohibición de

23 Corte Interamericana de Derecho Humanos, Caso Castillo Petruzzi y otros c. Perú, Sentencia de 30 de mayo de 1999 (Fondo, Reparaciones y Costas), párr.226. 13 y 14.

24 CASSEL, D., «El Perú se retira de la Corte: ¿Afrontará el reto el Sistema Interamericano de Derechos Humanos?», Revista IIDH, nº 29 (enero-junio 1999), San José de Costa Rica 2000, p.70.

25 Cfr. Corte Interamericana de Derechos Humanos, caso de la Comunidad Mayagna (Sumo) Awas Tingni c. Nicaragua (Fondo, Reparaciones y Costas), sentencia de 31 de agosto de 2001, párr. 153.

26 Corte Interamericana de Derechos Humanos, caso «La Última Tentación de Cristo» (Olmedo Bustos y otros c. Chile), sentencia de 5 de febrero de 2001 (Sentencia, Reparaciones y Costas), punto resolutivo 4.

27 Corte Interamericana de Derechos Humanos, caso Gelman c. Uruguay, sentencia de 24 de febrero de 2011 (Fondo y Reparaciones), párr.232. 
practicar dicho tratamiento ${ }^{28}$. No obstante, a día de hoy, esta sentencia emitida en noviembre del 2012 aún no ha sido cumplida en su totalidad como deja dicho la Corte Interamericana en la resolución de supervisión notificada el 1 de marzo de 2016 al Gobierno de Costa Rica. En esta resolución, la Corte, deja constancia que este país no obstante al efecto inmediato y vinculante que debería tener la sentencia aún mantiene la prohibición de la fecundación in vitro. En palabras de la Corte, en Costa Rica debe entenderse que está técnica de producción está autorizada y se debe permitir tanto a nivel privado como público $^{29}$.

b) La incorporación de control de convencionalidad en el Sistema

Introdujo en su jurisprudencia el control de convencionalidad, de la mano del ex juez Sergio García Ramírez quien en el 2003 en el caso de Myrna Mack Chang ya había hecho referencia al tema, por vez primera en el caso Almonacid Arellano contra Chile en el 2006 al señalar que los jueces y tribunales internos de un Estado que haya ratificado un tratado internacional como es el caso de la Convención Americana están sometidos a ella, en el marco de sus respectivas competencia, y deben velar porque los efectos de las disposiciones de la Convención no se vean reducidas por la aplicación de leyes contrarias a su objeto y fin. En palabras de la Corte «(...) el Poder Judicial debe ejercer una especie de «control de convencionalidad» entre las normas jurídicas internas que aplican en los casos concretos y la Convención Americana sobre Derechos Humanos. En esta tarea, el Poder Judicial debe tener en cuenta no solamente el tratado, sino también la interpretación que del mismo ha hecho la Corte Interamericana, intérprete última de la Convención Americana ${ }^{30}$.

La Corte, de la práctica, advierte que varios tribunales nacionales entienden que la jurisprudencia internacional es fuente de derecho y utilizan la jurisprudencia de ésta para fundamentar sus decisiones e interpretacio-

28 Corte Interamericana de Derechos Humanos, caso Artavia Murillo y otros (Fecundación in vitro) c. Costa Rica, sentencia (Excepciones Preliminares, Fondo, Reparaciones y Costas), sentencia de 28 de noviembre de 2012, párr.336.

29 Corte Interamericana de Derechos Humanos, Resolución sobre supervisión de cumplimiento de sentencia. En <www.corteidh.or.cr/docs/comunicados/cp_03_16.pdf> [última visita: 3-032016].

30 Cfr. Sentencia de 26 de septiembre de 2006, párr. 124. Un estudio detallado sobre el tema puede verse en: GARCÍA RAMíreZ, S., «El control judicial interno de convencionalidad», Revista del Instituto de Ciencias furídicas de Puebla, V (28) (2011), pp. 123-159. 
nes $^{31}$. De esta forma, en palabras de este órgano judicial, se ha instaurado un control dinámico y complementario de las obligaciones convencionales de los Estados de respetar y garantizar derechos humanos, conjuntamente entre las autoridades internas (primariamente obligadas) y las instancias internacionales (en forma complementaria), de modo que los criterios de decisión puedan ser conformados y adecuados entre sí.

Así, «la jurisprudencia de la Corte muestra casos en que se retoman decisiones de tribunales internos para fundamentar y conceptualizar la violación de la Convención en el caso específico. En otros casos se ha reconocido que, en forma concordante con las obligaciones internacionales, los órganos, instancias o tribunales internos han adoptado medidas adecuadas para remediar la situación que dio origen al caso; ya han resuelto la violación alegada; han dispuesto reparaciones razonables, o han ejercido un adecuado control de convencionalidad $\gg^{32}$.

El control de convencionalidad es un desarrollo propio del sistema interamericano, no existe nada similar en otros sistemas de protección de los derechos humanos, que «exige» al Estado, a través de su órgano judicial, la aplicación de la CADH y la interpretación que realiza sobre este la Corte Interamericana en su derecho interno. Se entiende que el control de convencionalidad se hace extensivo a todos los instrumentos ratificados por los Estados y sobre los que la Corte se ha pronunciado, como es el caso de Convención Interamericana para Prevenir y Sancionar la tortura y Convención Interamericana para prevenir, sancionar y erradicar la violencia contra la mujer (Belem do Pará).

c) El desarrollo del derecho al debido proceso y las opiniones consultivas

$\mathrm{Al}$ hacer referencia a la jurisprudencia no podemos dejar de mencionar el aporte realizado por este órgano judicial en lo que al debido proceso se refiere. Paradójicamente ésta amplia interpretación del artículo 8 de la Convención Americana denominada garantías judiciales se debe a su constante vulneración por cuanto es uno de los artículos más violados de la Convención Americana ${ }^{33}$.

31 Corte Interamericana de Derechos Humanos, cuadernillo de jurisprudencia, $\mathrm{n}^{\circ} 7$, Control de Convencionalidad, 2015, párr. 86.

32 Corte Interamericana de Derechos Humanos, Informe Anual 2014, p.40-41.

33 Un amplio estudio sobre este artículo véase: QUISPE REMÓN, F., El derecho al debido proceso en el derecho internacional y en el sistema interamericano, Tirant lo Blanch, 2010, p. 645. 
Respecto al debido proceso es de señalar dos opiniones consultivas, la OC$16 / 99$ y la OC-18/2003.

La OC-16/99 El Derecho a la Información sobre la Asistencia Consular en el Marco de las Garantías del Debido Proceso Legal cuya importancia radica porque amplía el catálogo de derechos recogido en el artículo 8 de la CADH, introduciendo como un derecho fundamental bajo el paraguas del debido proceso el derecho de un extranjero a la información sobre la asistencia consular. La Corte considera necesario para atender al principio de igualdad ante la ley y que un proceso alcance sus objetivos, resolver los factores de desigualdad real de quienes se encuentran ante la justicia. Por ello, en palabras de este órgano judicial es esencial adoptar medidas de compensación que contribuyan a reducir y eliminar obstáculos que impidan la defensa eficaz de los propios intereses, ya que no se puede hablar de debido proceso si existen situaciones de desigualdad o desventaja. Por este motivo atribuye al extranjero el derecho a ser informado oportunamente de que puede contar con la asistencia consular.

El aporte de esta opinión consultiva, tras una interpretación exhaustiva de la Convención de Viena sobre las Relaciones Consulares de 24 de abril de 1963 (CV63), especialmente del art. 36 de la CV63, ha sido reconocer al detenido extranjero derechos individuales a los que corresponden deberes correlativos a cargo del Estado receptor ${ }^{34}$. Considera como un derecho fundamental, parte del debido proceso, la información sobre la asistencia consular a un extranjero detenido en el momento de la privación de la libertad o antes de rendir su primera declaración ante la autoridad.

En la OC-18/2003 sobre la Condición jurídica y Derechos de los Migrantes Indocumentados ante la pregunta de si el principio de no discriminación y el derecho a la protección igualitaria y efectiva de la ley pueden considerarse de ius cogens, la respuesta ha sido positiva y señaló que el principio de igualdad y no discriminación forma parte del derecho internacional general por cuanto es aplicable a todo Estado, independientemente de que sea parte o no en determinado tratado internacional y por ende se trata de un obligación erga omnes que vinculan a todos los Estados y generan efectos respecto a terceros, inclusive particulares ${ }^{35}$.

34 Corte Interamericana de Derechos Humanos, OC-16/99 solicitada por los Estados Unidos mexicanos, El Derecho a la Información sobre la Asistencia Consular en el marco de las Garantías del Debido Proceso Legal, 1 de octubre de 1999, párr.84.

35 Cfr. Corte Interamericana de Derechos Humanos, OC-18/2003 solicitada por los Estados unidos mexicanos, Condición Jurídica y Derechos de los Migrantes Indocumentados, 17 de septiembre de 2003, punto resolutivo 5 . 
La Corte señala que «generalmente los inmigrante se encuentran en situación de vulnerabilidad como sujetos de derechos humanos, en una condición individual de ausencia o diferencia de poder con respecto a los no-migrantes (nacionales o residentes). Esta condición de vulnerabilidad tiene una dimensión ideológica y se presenta en un contexto histórico que es distinto para cada Estado, y es mantenida por situaciones de jure (desigualdades entre nacionales y extranjeros en las leyes) y de facto (desigualdades estructurales). Esta situación conduce al establecimiento de diferencias en el acceso de unos y otros a los recursos públicos administrados por el Estado» ${ }^{36}$. Justamente esto llevo a regular internacionalmente la protección de los derechos humanos de los inmigrantes. Deja claro, la Corte, en esta opinión la existencia de una obligación estatal general, reconocido en diversos instrumentos internacionales, de respetar y garantizar los derechos humanos así como lo incuestionable del reconocimiento de atributos inherentes a la dignidad humana que tiene toda persona y que son superiores al Estado, al margen de cuál sea su organización política. En esa línea señala la existencia de un vínculo indisoluble entre la obligación general de respetar y proteger los derechos humanos y el principio de igualdad y no discriminación ${ }^{37}$.

Si bien los Estados en el ejercicio de su facultad de establecer políticas migratoria pueden establecer medidas relacionadas con el ingreso, permanencia o salida de las personas inmigrantes para trabajar en los distintos sectores de producción, éstas deben ser acordes con las medidas de protección de los derechos humanos. Los Estados no pueden condicionar o subordinar la observancia del principio de la igualdad ante la ley y la no discriminación al cumplimiento de sus objetivos en materia de políticas públicas en ningún caso $^{38}$. Se trata de obligaciones que deben ser respetadas y garantizadas en cualquier circunstancia o consideración, incluida el estatus migratorio de las personas, debiendo adoptar medidas positivas, evitando tomar iniciativas que conculquen o limiten un derecho fundamental y suprimiendo prácticas que van en esa línea.

Uno de los aportes de esta opinión consultiva, además de garantizar el principio de la igualdad ante la ley y la no discriminación a todas las personas sin importar el estatus migratorio es el reconocimiento de estos principios

\footnotetext{
Idem, párr. 112.

7 Cfr. idem, párrs., 82-85.

38 Idem, párr.172.
} 
como normas de ius cogens debido a que «sobre él descansa todo el andamiaje jurídico del orden nacional e internacional y es un principio fundamental que permea todo el ordenamiento jurídico ${ }^{39}$. Este reconocimiento implica que todos los Estados, al margen de haber ratificado o no un instrumento internacional, deben dar pleno cumplimiento. Ser una norma imperativa de derecho internacional general hace que no pueda existir ningún argumento válido que impida su efectivo cumplimiento. Es erga omnes.

La Corte al abordar el principio de igualdad ante la ley y la no discriminación destaca la constante evolución del derecho internacional y hace mención a la opinión consultiva 16 que también, como mencionamos supra, amplía el catálogo de derechos protegidos al amparo del debido proceso. En ese contexto manifiesta que el debido proceso debe ser reconocido en el marco legal de las garantías mínimas que se le debe reconocer a cualquier inmigrante, al margen de su estatus migratorio. La intangibilidad del debido proceso se aplica sin discriminación alguna a todas las materias y todas las personas.

Un aspecto a destacar de esta opinión consultiva es el reconocimiento del papel que desempeña el debido proceso en el ejercicio efectivo de cualquier derecho de carácter dispositivo e incluso imperativo, como es el caso. Se trata de un derecho que debe ser garantizado a toda persona ${ }^{40}$ al margen de la gravedad del delito que hubiera cometido.

d) Las reparaciones y su desarrollo a la luz de la jurisprudencia

Por otro lado, no podemos dejar de mencionar la interpretación colosal que ha venido realizando la Corte interamericana desde sus inicios del artículo 63.1 de la CADH referido a la reparación. Este artículo señala «Cuando decida que hubo violación de un derecho o libertad protegidos en esta Convención Americana, la Corte dispondrá que se garantice al lesionado en el goce de su derecho o libertad conculcados. Dispondrá asimismo, si ellos fuera procedente, que se reparen las consecuencias de la medida o situación que ha configurado la vulneración de esos derechos y el pago de una justa indemnización a la parte lesionada».

Es un artículo escueto que no determina las clases ni las formas de reparación, no obstante desde su primera sentencia este órgano judicial teniendo

39 Idem, párr.101.

40 Cfr. Párrs.120-126. 
en cuenta los instrumentos internacionales de derechos humanos a nivel universal y regional, así como la jurisprudencia desarrollada a nivel internacional sobre la materia -Corte Permanente del Tribunal Internacional de Justicia en el caso Factory at Chorzów (1927)- manifestó que se trata de un principio de Derecho internacional y que toda violación a una obligación internacional que haya producido un daño implica el deber de repararlo adecuadamente ${ }^{41}$. Destacó que la forma más usual de hacerlo es la indemnización. Asimismo señaló que la reparación del daño derivado de una infracción a una obligación internacional consiste en la plena restitución (restitutio in integrum), «lo que incluye el establecimiento de la situación anterior y reparación de las consecuencias que la infracción produjo y el pago de una indemnización como compensación por los daños patrimoniales y extra patrimoniales incluyendo el daño moral $\gg^{42}$. Sostuvo además que la sentencia en sí misma constituye una forma de reparación y satisfacción moral para las víctimas. De esta forma, considerando que el art. 63.1 de la Convención recoge uno de los principios fundamentales del derecho internacional general y teniendo en cuenta que la reparación es el término genérico que comprende las diferentes formas de cómo un estado puede hacer frente a la responsabilidad internacional en que ha incurrido un Estado ${ }^{43}$ ha venido desarrollando y dando contenido al concepto de reparación en el sistema interamericano de protección de los derechos humanos. En ella incluye el restitutio in integrum, la indemnización que incluye el daño material (daño emergente y lucro cesante) e inmaterial (daño moral y reintegro de costas y gastos), satisfacción, rehabilitación (asistencia médica y psicológica), garantías de no repetición, entre otras ${ }^{44}$.

La Corte desde su primera sentencia destaca que el objeto del DIDH no es imponer penas a las personas culpables de sus violaciones, sino amparar a las víctimas y disponer la reparación de los daños que les hayan sido causados por

41 Corte Interamericana de Derechos Humanos, caso Velásquez Rodríguez c Honduras, sentencia de 21 de julio de 1989 (Reparaciones y Costas), párr. 25.

42 Idem, párrs. 26.

43 Corte Interamericana de Derechos Humanos, Caso Loayza Tamayo c Perú, sentencia de 27 de noviembre de 1997 (Reparaciones y Costas), párr.85.

44 Respecto a las reparaciones, la Corte va en la misma línea de lo establecido en la Resol. 2005/35 de la aquel entonces Comisión de Derechos Humanos de las Naciones Unidas sobre los Principios y directrices básicos sobre el derecho de las víctimas de violaciones de las normas internacionales de derechos humanos y del derecho internacional humanitario a interponer recursos y obtener reparaciones (E/CN.4/RES/2005/35). Dentro de estos principios en el punto IX se hace referencia a la reparación de los daños sufridos y en él se incluyen la restitución, indemnización, rehabilitación, satisfacción, garantías de no repetición. 
los Estados responsables de tales acciones ${ }^{45}$. Así, de sus sentencias advertimos que el objetivo de la Corte no solo es compensar económicamente a la víctima, sino realmente intentar satisfacer los daños causados a través de una reparación integral, que va más allá del aspecto económico. Además de ello, como señala García Ramírez, «la materia de reparaciones ha sido el puente para que ingresen al sistema interamericano algunas novedades útiles en materia de legitimación procesal activa, que prefiguran la posibilidad de que el lesionado, concurra a través de un verdadero derecho subjetivo, a la preservación de un orden jurídico objetivo» ${ }^{46}$. Se refiere al Reglamento de la Corte de 1996 cuyo artículo 23 le confiere legitimación activa procesal a la víctima cuando señala «en la etapa de reparaciones los representantes de la víctimas o de sus familiares podrán presentar sus propios argumentos y pruebas en forma autónoma».

e) La nueva concepción del juez ad hoc en el sistema interamericano

Si bien en este apartado nos referimos a la interpretación amplia de los artículos de la $\mathrm{CADH}$ tanto en sentencias como en opiniones consultivas, es de destacar la OC-20/09 sobre el artículo 55 de la Convención Americana dado que modifica radicalmente una práctica habitual de la Corte respecto a los jueces ad hoc e hizo que la Corte modificara su reglamento incluyendo en el artículo 19 que el juez nacional de un Estado parte en un caso ante la Corte no podrá participar en el conocimiento y deliberación del mismo si se trata de una petición individual. En el artículo 20 deja dicho que solo se nombrarán jueces ad hoc en casos originados en comunicaciones interestatales. El uso hasta antes del Reglamento del 2009 de los jueces ad hoc en la Corte era para representar al Estado demandado cuando no hubiera un juez de la nacionalidad de dicho Estado y participar junto a los otros jueces en las deliberaciones. Sin duda se trata de una modificación lógica y coherente teniendo en cuenta la igualdad de las partes en el proceso.

De este modo el desarrollo de los derechos humanos en esta parte del mundo se ha dado a través de sus dos órganos. El primero un órgano político y cuasi judicial (la Comisión) y el segundo el órgano judicial del sistema (La

45 Corte Interamericana de Derechos Humanos, caso Velásquez Rodríguez c. Honduras, sentencia de 29 de julio de 1988 (Fondo), párr. 134.

46 Cfr. <www.cepc.es/rap/Publicaciones/Revistas/8/AIB_003_329.pdf>, pp. 333 [última visita: 042015]. 
Corte). Cada uno de ellos se ha ido pronunciando sobre la violación de los derechos dependiendo de la ratificación de la Convención Americana por parte de los Estados, así como teniendo en cuenta la obligación de los Estados por haber asumido la competencia contenciosa de la Corte Interamericana.

Así, advertimos tanto de la CADH como de la jurisprudencia que los Estados tienen la obligación de cumplir con la protección de los derechos recogidos en la Convención y en la Declaración Americana, así como el de atender las decisiones del órgano judicial del sistema interamericano. Este último se afianza cada vez más a través del control de convencionalidad a la que viene haciendo referencia la Corte Interamericana en sus decisiones a partir del 2006. Pero, lamentablemente, de la práctica se advierte que para una protección real y efectiva no basta solo la existencia de magníficos instrumentos internacionales ni sentencias garantistas pro homini. La efectividad va más allá y requiere, fundamentalmente, de una actuación más comprometida y rápida por parte de los Estados en el cumplimiento de las sentencias. Siempre se ha dicho que una justicia lenta no es justicia y esto sería también aplicable y exigible en el ámbito internacional ya sea en la duración del proceso en el órgano judicial internacional como en el cumplimiento de las decisiones emanadas de éste por parte del Estado.

\section{MEDIDAS DE ACCESO A LA JUSTICIA INTERNACIONAL AMERICANA: UN AVANCE EN LA PROTECCIÓN DE LOS DERECHOS HUMANOS}

En este sistema, a diferencia del sistema europeo, los individuos directamente no pueden plantear sus casos ante la Corte Interamericana, sino deben necesariamente hacerlo a través de la Comisión Interamericana, quien desempeña un papel de filtro para que los casos sean conocidos por la Corte. No obstante las modificaciones en las dos últimas décadas en los Reglamentos de la Corte han ido otorgando cierto papel al individuo ante este órgano judicial. Es el caso del Reglamento de 1996 de la Corte Interamericana cuyo artículo 23 les otorga inicialmente a los representantes de las víctimas o de sus familiares, en la etapa de reparaciones, la potestad de presentar sus propios argumentos y pruebas en forma autónoma. Cuatro años más tarde en su Reglamento del año 2000 también en el artículo 23 amplía la participación, de forma autónoma, de las presuntas víctimas, sus familiares o sus representantes acreditados, después de la admisión de la demanda presentando solicitudes, argumentos durante todo el proceso. Dejando dicho que ante la pluralidad de presuntas víctimas 
y/o representantes debe nombrarse un interviniente común, que será el autorizado para participar en el proceso, incluida la audiencia pública.

De esta forma el sistema interamericano reconoce el locus standi in juicio. Un gran paso, sin lugar a dudas dado el contexto de una Corte no permanente. Aspirar al fus standi implicaría previamente contar con una Corte de carácter permanente, reestructurada, que pueda hacer frente a todas las demandas planteadas directamente por las personas sin pasar por la Comisión. Desde luego esto no garantiza automáticamente la efectividad del sistema. En el ámbito europeo a partir del Protocolo once, las personas tienen acceso directo al Tribunal y esto ha traído como consecuencia un alto número de demandas al que el Tribunal no logra dar trámite, tal es así que a día de hoy esto constituye uno de los principales problemas del sistema, por lo que, entre otras medidas, se adoptó el Protocolo 14 que entró en vigor en junio del 2010, el cual ha incrementado el nivel de exigencia en relación con los requisitos de admisibilidad y establece, entre otros, la existencia de un «perjuicio importante», además ha introducido cambios en las formaciones judiciales del tribunal orientados a agilizar su actuación y reducir el gran retraso en el trámite de los casos.

\section{El establecimiento del Fondo de Asistencia Legal}

A fin de brindar una mejor protección al ser humano en esta parte del mundo, la Asamblea General de la OEA en el 2008 dispuso la creación del Fondo de Asistencia Legal del Sistema Interamericano de Derechos Humanos $^{47}$. Dicho fondo tendrá dos cuentas separadas, una para la Comisión Interamericana y otra para la Corte Interamericana y se compondrá de contribuciones voluntarias de los Estados Miembros de la OEA, de los Estados observadores, y de otros Estados y donantes que deseen colaborar. El objeto del Fondo es «facilitar el acceso al sistema interamericano de derechos humanos a aquellas personas que actualmente no tienen recursos necesarios para llevar su caso al sistema». Una creación sin duda loable, pero si se tiene en cuenta que este fondo no cuenta con recursos del presupuesto ordinario de la

47 (OEA) AG/RES/2426 de 3 de junio de 2008. Esta resolución entraría en vigor una vez el Consejo Permanente de la OEA apruebe su reglamento. El 11 de noviembre de 2009, el Consejo Permanente de la OEA mediante Resolución 963 aprobó el Reglamento para el funcionamiento del Fondo de Asistencia Legal del sistema interamericano de derechos humanos. 
$\mathrm{OEA}^{48}$ su efectividad dependerá de las contribuciones que buenamente realicen otras instituciones.

El cuatro de febrero de 2010 la Corte Interamericana adoptó el Reglamento sobre el funcionamiento del Fondo de Asistencia Legal de víctimas que entró en vigor el uno de junio del 2010. Se trata de un documento que regula el acceso y funcionamiento de dicho fondo. La solicitud de este fondo se debe hacer ante la Corte en el escrito de solicitudes, argumentos y pruebas demostrando a través de una declaración jurada y otros medios idóneos que carece de medios económicos para hacer frente a los gastos del litigio ante la Corte y precisar qué aspectos de su defensa requiere el uso del Fondo. El Presidente de la Corte resolverá en el plazo de tres meses desde la recepción de los documentos requeridos. La encargada de administrar el Fondo de Asistencia Legal de Víctimas será la Secretaría de la Corte, quién, una vez se haya decidido la procedencia de la solicitud y se haya notificado ésta, abrirá un expediente en el que documentará el reparto que se realice de acuerdo a lo autorizado por la Presidencia. La Secretaría será la encargada de informar al Estado demandado los gastos realizados para que si lo considere presente sus observaciones. En el momento de emitir sentencia, la Corte «evaluará la procedencia de ordenar al Estado demandado el reintegro, al Fondo de Asistencia Legal correspondiente a la Corte Interamericana de Derechos Humanos, las erogaciones en que hubiese incurrido» ${ }^{49}$. Desde el 2010 hasta la fecha en más de cincuenta casos, el presidente de la Corte se ha pronunciado sobre la petición para acogerse al Fondo $^{50}$.

No cabe duda de las buenas intenciones de la OEA en la creación de este fondo, pero lamentablemente su eficacia dependerá de otros entes por cuanto el presupuesto de la OEA no lo contempla. La Corte Interamericana ha ido buscando contribuciones voluntarias para asegurar la existencia y funcionamiento de éste. Dichas contribuciones provienen de proyectos de cooperación (Noruega 70\% y Dinamarca 25\%), y de la voluntad de los Estados (Colombia $5 \%)^{51}$.

48 Cfr. Informe Anual 2014 de la Corte Interamericana, p. 85.

49 Reglamento de la Corte Interamericana sobre el Funcionamiento del Fondo de Asistencia Legal de víctima, artículo 5 .

50 Cfr. <www.corteidh.or.cr/cf/jurisprudencia2/busqueda_fondo_asistencia.cfm?lang=es> [última visita: 03-2016].

51 Informe Anual 2014, op. cit., p. 85. 


\section{La creación del Defensor Interamericano}

La Corte Interamericana en la línea de ofrecer cada vez más una mejor protección al ser humano, en su último Reglamento, teniendo en cuenta la realidad económica de la región y de las víctimas procedió a la creación del Defensor Interamericano al que definió en su artículo 2.11 como la persona designada por la Corte para que asuma la representación legal de una presunta víctima que no designó por sí mismo un defensor ${ }^{52}$. El artículo 37 consagra la figura del Defensor Interamericano al señalar «en casos de presuntas víctimas sin representación legal debidamente acreditada, el Tribunal podrá designar un Defensor Interamericano de oficio que las represente durante la tramitación del caso». El Defensor Interamericano pasa a ser el representante legal de la presunta víctima ante la Corte Interamericana. Tal es así que a partir de su nombramiento la Secretaría notificará del caso al Defensor Interamericano, si fuera el caso.

El objetivo de la Corte con la creación de esta figura es ofrecer a todas las personas el acceso a la justicia internacional para ejercer la defensa en ella y hacer valer sus derechos y libertades. Consiste en proveer de asistencia legal gratuita a las personas que lo necesitan y no pueden cubrir los costos que ello implica. Esto a través del Acuerdo de Entendimiento celebrado entre la Corte y las Asociación Interamericana de Defensorías públicas (AIDEF) ${ }^{53}$. La Corte ejerce de intermediario entre la AIDEF y la presunta víctima por cuanto ante la necesidad de una representación legal de la presunta víctima la Corte comunicará al coordinador general de la AIDEF para que designe en el plazo de diez días al defensor/a, que asumirá la representación legal y defensa, y establezca el lugar donde se deben realizar las notificaciones. Luego la Corte comunicará a la presunta víctima el nombre del defensor/a que le representará y defenderá en el caso ante la Corte. La Corte correrá con los gastos del defensor interamericano, en la medida de sus posibilidades, a través del Fondo de Asistencia Legal de Víctimas.

52 El 11 de noviembre de 2009, el Consejo Permanente de la OEA al aprobar el Reglamento para el funcionamiento del Fondo de Asistencia Legal del sistema interamericano de derechos humanos mediante Resolución 963, en su artículo 4.2.b señaló: «El establecimiento de un sistema gratuito de defensoría de oficio en ambos órganos para las personas que lo necesiten, de conformidad con los recursos asignados por dicho Fondo».

53 Del 25 de septiembre 2009 que entró en vigor el 1 de enero del 2010. La AIDEF es una institución de carácter civil no lucrativa, apolítica integrada por Instituciones estatales de Defensorías Públicas y Asociaciones de Defensores Públicos de América que tienen a su cargo la representación, asesoría y defensa técnica en juicio de personas según las leyes, constituciones y tratados internacionales, cuyos fines son, entre otros, la defensa de los derechos humanos. 
Dos años más tarde de la aprobación del último Reglamento de la Corte en el que se reconoce el Defensor Interamericano, el 15 de abril del 2011, en el caso Furlan contra Argentina ${ }^{54}$, el Sr. Furlan solicitó la designación de un defensor interamericano. La Corte trasladó dicha solicitud a la AIDEF, el 25 de abril ésta informo la designación de dos defensores interamericanos, una argentina y un uruguayo, como representante de las presuntas víctimas para su representación legal en dicho caso. Luego estos representantes solicitaron acogerse al Fondo de Asistencia Legal de víctimas de la Corte Interamericana, petición que fue declarada procedente por el Presidente de la Corte, quien determinó que «se otorgará la asistencia económica necesaria para solventar los gastos razonables y necesarios que han sido acreditados y que sean acreditados por los defensores con el fin de llevar a cabo la tramitación del caso ante este Tribunal, y que el monto, destino y objeto específicos de dicha asistencia serán precisados al momento de decidir sobre la evacuación de prueba pericial y testimonial y, en su caso, la apertura del procedimiento oral en los términos del artículo 50 del Reglamento del Tribunal, de conformidad con lo establecido en los párrafos considerativos 15 a 19 de esta Resolución ${ }^{55}$.

Desde entonces la participación del Defensor Interamericano y el Fondo de asistencia Legal para las víctimas ha sido positiva y ha permitido el acceso de las personas, al margen de su situación económica, para poder hacer valer sus derechos. Así la Corte Interamericana en su Informe Anual ha dejado claro que «Los casos en los que el Defensor Interamericano ha asumido la defensa de víctimas y la puesta en funcionamiento del Fondo de Asistencia Legal de Víctimas han permitido solventar los gastos de comparecencia en juicio a decenas de víctimas, testigos, peritos y abogados» ${ }^{56}$.

\section{Posibles debilidades Del Sistema: aspectos A ReForZar}

\section{Los Estados y el cumplimiento de sentencias}

La vigencia y efectividad del Sistema Interamericano pasa, no solo por contar con instrumentos jurídicos protectores y sentencias u opiniones consultivas progresistas y maravillosas sino por el cumplimiento a cabalidad por

54 Corte Interamericana de Derechos Humanos, caso Furlan y familiares c. Argentina, sentencia del 31 de agosto del 2012 (Excepciones preliminares, Fondo, reparaciones y Costas), párr.5.

55 Resolución del Presidente de la Corte Interamericana de Derechos Humanos de 23 de noviembre de 2011, Fondo de Asistencia Legal de Víctimas caso Furlan y Familiares c. Argentina.

56 Corte Interamericana de Derechos Humanos, Informe Anual 2013, San José-Costa Rica 2014, p. 2. 
parte de los Estados de las sentencias expedidas por el órgano judicial de este sistema en un tiempo razonable teniendo en cuenta el compromiso asumido por los Estados a la hora de ratificar dichos instrumentos y asumir la competencia contenciosa de la Corte. Caso contrario la efectividad del Sistema estaría en entredicho y las sentencias serían papel mojado. Una frustración más para la víctima que ya tuvo que padecer la indiferencia o ineficacia del Estado en un primer momento al no brindarle la protección por la violación a los derechos humanos y verse obligado a activar la jurisdicción internacional, y en segundo momento al ver el incumplimiento por parte del Estado de lo ordenado en la sentencia emitida por un órgano judicial internacional.

Si bien existe un gran avance por parte de los órganos de protección de los derechos humanos, especialmente por parte de la Corte Interamericana en materia de reparaciones en el sistema interamericano, desafortunadamente el cumplimiento a cabalidad de las órdenes de reparación por parte de los Estados sigue siendo una tarea pendiente. La parte que se cumple con más facilidad está relacionada con la reparación económica y no así con las otras reparaciones $^{57}$. Así, del informe emitido por parte de la Corte Interamericana en el 2009, de 120 casos que la Corte ha resuelto desde 1979 hasta finales de 2009, 104 se encontraban en la etapa de supervisión de cumplimiento de sentencia ${ }^{58}$. Del último informe (2015) de la Corte se tiene que 157 casos se encuentran en estado de supervisión ${ }^{59}$. Dentro de los cuales figuran sentencias de 1996, 1997, 1998 en adelante como es el caso Neira Alegría contra Perú, Caballero Delgado y Santana contra Colombia, Benavides Zevallos contra Ecuador, Panel Blanca contra Guatemala ${ }^{60}$. Esto es un claro ejemplo de la falta de

57 Por ejemplo en el caso Artavia Murillo y Otros (fecundación in vitro) c. Costa Rica, al que ya hicimos referencia, el Estado cumplió con publicar la sentencia, implementar programas y cursos permanentes de educación y capacitación en derechos humanos, derechos reproductivos y no discriminación, pagar las indemnizaciones a las víctimas y viene también cumpliendo con la atención sicológica gratuita a las víctimas, PERO no ha cumplido con lo esencial: dejar sin efecto la ley que prohíbe la fecundación in vitro.

58 Cfr. Corte Interamericana de Derechos Humanos, Informe Anual 2009, pp. 4-8, <www.corteidh. or.cr/sitios/informes/docs/SPA/spa_2009.pdf> [última visita: 12-2015].

59 Corte Interamericana de Derechos Humanos, OEA, Informe Anual 2015, pp. 86-90, <www.corteidh.or.cr/tablas/informe2015/espanol.pdf> [última visita: 03-2016].

60 A septiembre de 2015 figuran 167 casos en supervisión. 13 casos contra Argentina, 2 contra Barbados, 3 contra Bolivia, 3 contra Brasil, 6 contra Chile, 15 contra Colombia, 1 contra Costa Rica, 11 contra Ecuador, 5 contra El Salvador, 19 contra Guatemala, 2 contra Haití, 9 contra Honduras, 6 contra México, 1 contra Nicaragua, 4 contra Panamá, 6 contra Paraguay, 34 contra Perú, 4 contra República Dominicana, 3 contra Surinam, 3 contra Trinidad y Tobago, 2 contra Uruguay y 16 contra Venezuela. Cfr. <www.corteidh.or.cr/cf/jurisprudencia2/casos_en_etapa_ de_supervision.cfm> [última visita: 01-2016]. 
cumplimiento en la ejecución total de las sentencias por parte de los Estados transcurrido casi dos décadas desde la emisión de las mismas ${ }^{61}$. Situación ésta que lamentablemente desmerece la efectividad del sistema interamericano, no obstante al esfuerzo que realizan sus órganos en la protección de los derechos humanos. Para la Corte el cumplimiento efectivo de sus decisiones son parte integrante del derecho de acceso a la justicia.

Visto el incumplimiento de las decisiones emanadas por parte de la Corte Interamericana nos preguntamos en qué medida funciona el control de convencionalidad a la que viene haciendo referencia la Corte Interamericana desde hace unos años atrás. Se entiende que este control de convencionalidad significa para un Estado que es parte de un tratado internacional como la Convención Americana que todos sus órganos, incluidos los jueces, están sometidos a aquél y a las decisiones que emanan de su órgano judicial ${ }^{62}$. El Estado debe tener presente en todo momento que un caso no se «cierra» en el sistema interamericano hasta el cumplimiento total y absoluto de lo indicado en la sentencia y actuar en consecuencia. De la práctica se advierte retardos en el cumplimiento de las sentencias que superan en exceso cualquier plazo razonable.

\section{La supervisión del cumplimiento de las sentencias de la Corte Interamericana: un aspecto clave en la efectividad del Sistema}

En el sistema interamericano de protección de los derechos humanos, si revisamos la $\mathrm{CADH}$ no encontramos una referencia explícita sobre quien

61 En el seno de la OEA, los Estados son conscientes de los aspectos que se deben fortalecer en el continente americano. Así, se desprende, entre otros, de la AG/RES 1890 (XXXII-O-02) Evaluación del Funcionamiento del Sistema Interamericano de Protección y Promoción de los Derechos Humanos para su Perfeccionamiento y Fortalecimiento (4 de junio de 2002), donde los jefes de Estado y de Gobierno en el Plan de Acción de la Tercera Cumbre de las Américas, decidieron continuar promoviendo acciones concretas para fortalecer y perfeccionar el sistema interamericano de derechos humanos, en particular el funcionamiento de la Corte Interamericana de Derechos Humanos y la Comisión Interamericana de Derechos Humanos, concentrándose en la universalización del sistema interamericano, el aumento de adhesiones a sus instrumentos fundamentales, el cumplimiento de las decisiones de la Corte y el seguimiento de las recomendaciones de la Comisión, la facilitación del acceso de las personas a este mecanismo de protección, el incremento sustancial de los fondos asignados para mantener sus operaciones en curso, incluidos incentivos para fomentar contribuciones voluntarias, y el examen de la posibilidad de que la Corte y la CIDH funcionen de manera permanente. En este contexto resolvieron: Reafirmar la voluntad de la OEA de continuar las acciones concretas tendientes al cumplimiento de los mandatos de los Jefes de Estado y de Gobierno relacionadas con el fortalecimiento y perfeccionamiento del sistema interamericano de derechos humanos contenidas en el Plan de Acción de la Tercera Cumbre de las Américas, donde se incluye el cumplimiento de las decisiones de la Corte y el seguimiento de las recomendaciones de la Comisión

62 Corte Interamericana de Derechos Humanos, Informe Anual 2015, ob. cit. p.41. 
o quienes serán los encargados de hacer seguimiento al cumplimiento de las decisiones de la Corte Interamericana. No existe un órgano encargado de supervisar o hacer el seguimiento al cumplimiento de las decisiones que emite la Corte ${ }^{63}$. El único artículo relacionado con el tema es el 65, el cual establece que «La Corte someterá a la consideración de la Asamblea General de la Organización en cada período ordinario de sesiones un informe sobre su labor en el año anterior. De manera especial y con las recomendaciones pertinentes, señalará los casos en que un Estado no haya dado cumplimiento a sus fallos» ${ }^{64}$. De ello se infiere la obligación de la Corte de emitir un informe de sus labores a la Asamblea General de la OEA, donde debe mencionar, especialmente, los casos en que un Estado no haya dado cumplimiento a sus fallos, pero en ningún caso establece que la Corte será la encargada de supervisar la ejecución de sus propias sentencias, ni su reglamento establecía inicialmente el o los mecanismos para hacerlo. No obstante, en el art. 65 de la CADH está la fuente de la facultad que la Corte tiene para supervisar el cumplimiento de sus decisiones ${ }^{65}$.

En base a este artículo la Corte se auto atribuye la facultad para supervisar el cumplimiento de sus decisiones. Desde el 2001 viene emitiendo resoluciones de cumplimiento de sus sentencias, de donde se advierte el grado de cumplimiento y las gestiones realizadas tanto por la Corte como por los Estados y las demás partes. Para este órgano judicial no cabe duda que se trata de una potestad inherente a sus funciones jurisdiccionales ${ }^{66}$, así lo ha venido

63 En el sistema europeo de protección de los derechos humanos este papel lo desempeña el Comité de Ministros.

64 Lamentablemente la Organización no adopta ninguna medida que implique «una presión» para el Estado que incumple con sus obligaciones y siendo ello así este artículo no resulta en ningún caso efectivo. A modo de ejemplo podemos citar el caso de Trinidad y Tobago donde la Corte en su informe pidió a la OEA que exhorte a cumplir con las resoluciones. Esto es, la Corte había ordenado medidas provisionales para salvaguardar y asegurar los derechos de los condenados a muerte no obstante, el Estado ejecutó a dos personas (informe 1998 y 1999). Pero no hubo respuesta de la OEA. Los informes de incumplimiento de una sentencia pasan sin pena no gloria. No es más que un informe. Ni la Asamblea General ni otro órgano de la OEA somete a debate el tema ni visibiliza el incumplimiento. Esta situación debilita el sistema y permite que los Estados puedan seguir incumpliendo sus compromisos.

65 La Corte Interamericana desde sus primeras sentencias se ha preocupado por hacer el seguimiento al cumplimiento de sus decisiones a través de sus comunicaciones enviadas a los Estados y a las partes y por los informes anuales dirigidos a la Asamblea General. Pero es a partir del 2001 cuando de manera uniforme encontramos las resoluciones sobre el cumplimiento de sus sentencias. Cfr. <www.corteidh.or.cr/supervision.cfm> [última visita: 03-2011].

66 Resolución de la Corte Interamericana de Derechos Humanos de 4 de julio de 2006, caso El Amparo. Cumplimiento de sentencia. 
reiterando en sus sentencias, cuando dice que será la encargada de supervisar el cumplimiento íntegro de la sentencia, en ejercicio de sus atribuciones y en cumplimiento de sus deberes conforme a la Convención Americana de Derechos Humanos ${ }^{67}$, y dará por concluido el caso una vez que el Estado haya dado cabal cumplimiento a lo dispuesto en la sentencia ${ }^{68}$. Se considera un caso en etapa de supervisión de cumplimiento de sentencia cuando la Corte ya ha resuelto el caso y se encuentra pendiente de cumplimiento por parte del Estado condenado, algún extremo de la sentencia. Solo cuando la Corte considera que el Estado ha cumplido con todas y cada una de las obligaciones ordenadas en la sentencia, se dispone el archivo del caso ${ }^{69}$.

La supervisión que ejerce la Corte se traduce en solicitar información al Estado, a la Comisión Interamericana y a las víctimas sobre el estado de cumplimiento de sus decisiones por parte del Estado. Con esa información, si lo considera puede convocar a una audiencia en su sede, como lo viene haciendo desde el $2007^{70}$, luego la Corte adopta la resolución, dejando establecido los puntos de la sentencia que se han cumplido y los que aún no se han cumplido. Ante puntos pendientes de cumplimiento insta al Estado a adoptar las medidas necesarias para dar cumplimiento en su integridad y si se han cumplido todos los extremos de la sentencia, declara su cumplimiento y ordena el archivamiento del caso.

El sistema interamericano en el 2009, entendemos que, dado el alto porcentaje de incumplimiento de sus decisiones y teniendo en cuenta el problema que constituye la falta de regulación a propósito de la supervisión de sus sentencias incluyó en el Reglamento de la Corte Interamericana una referencia expresa a este aspecto bajo el nombre: la supervisión de cumplimiento de sentencias ${ }^{71}$ donde se-

67 Entre otros véase: Corte Interamericana de Derechos Humanos, caso Garrido y Baigorria c. Argentina, sentencia de 27 de agosto de 1999 (Reparaciones y Costas), punto 7 de la parte resolutiva; caso Castillo Petruzzi y otros c. Perú, sentencia de 30 de mayo de 1999 (Fondo, Reparaciones y Costas), punto 16 de la parte resolutiva; y caso Valentina Rosendo Cantú c. México, sentencia de 13 de agosto de 2010 (Excepción Preliminar, Fondo, Reparaciones y Costas), párr. 25 del punto resolutivo.

68 En su primera sentencia hacía referencia como atribución a su competencia la supervisión de todo el proceso de cumplimiento de la indemnización compensatoria. Véase: caso Velásquez Rodríguez c. Honduras, sentencia de 21 de julio de 1989 (Reparaciones y Costas), párr. 59.

69 Véase el Informe de Corte Interamericana de 2009, Ob. cit., p. 11.

70 Del informe anual del 2015 se advierte que la Corte realizó este año ocho audiencias privadas de supervisión de cumplimiento y emitió siete resoluciones de supervisión de cumplimiento.

71 Reglamento de la Corte Interamericana de Derechos Humanos, aprobado por la Corte en su LXXXV Período Ordinario de Sesiones celebrado del 16 al 18 de noviembre de 2009, art. 69. Es de mencionar que en los tres reglamentos anteriores (1980, 1991 y 1996) no encontramos ninguna referencia a la supervisión de cumplimiento de sentencias. 
ñala que «la supervisión de las sentencias y demás decisiones de la Corte se realizará mediante la presentación de informes estatales y de las correspondientes observaciones a dichos informes por parte de las víctimas o sus representantes. La Comisión deberá presentar observaciones al informe del Estado y a las observaciones de las víctimas o sus representantes» (art. 69.1). Asimismo, establece que la Corte podrá requerir datos relevantes sobre el caso a otras fuentes de información, que permitan apreciar el cumplimiento. Para los mismos efectos podrá también requerir los peritajes e informes que considere oportunos. (69.2). Del mismo modo, establece que cuando la Corte lo considere pertinente, podrá convocar al Estado y a los representantes de las víctimas a una audiencia para supervisar el cumplimiento de sus decisiones, y en esta escuchará el parecer de la Comisión (69.3). Una vez que el Tribunal cuente con información pertinente, determinará el estado del cumplimiento de lo resuelto y emitirá las resoluciones que estime pertinentes. Ahora bien cabría preguntarse si ¿esta regulación es suficiente para lograr la ejecución íntegra de las sentencias?, ¿es un mecanismo sólido para que los derechos humanos sean realmente efectivos en este continente? considerando los escasos recursos con los que cuentan los órganos de protección del sistema y la falta de una Corte permanente.

La Corte, como sabemos, ejerce doble función, contenciosa y consultiva, y dentro de la primera conforme al procedimiento establecido en su Reglamento se encuentra la tarea de supervisar el grado de cumplimiento de las sentencias emitidas ${ }^{72}$. Es de observar que la supervisión al cumplimiento de las sentencia de la Corte está basada en los informes que los Estados presentan a la Corte Interamericana y en las observaciones que las víctimas o sus representantes realizan a estos. Es el propio Estado el encargado de informar sobre el cumplimiento o no de las decisiones de la Corte, no existiendo un órgano especial encargado de realizar una visita in situ al Estado, si fuera necesario, para informar sobre el cumplimiento de las sentencias de la Corte. La supervisión a la que hace referencia el Reglamento de la Corte no parece ser lo suficientemente efectiva. Así pues, siguiendo a García Ramírez podemos decir que la Corte «tiene una potestad ejecutiva limitada: solo en la extensión en la que ésta es admisible, hoy día, en el plano internacional y puede por ello, en palabras de este autor, mantenerse al tanto del cumplimiento de sus resoluciones e instar el acatamiento de los Estados» ${ }^{73}$. Destaca que los órganos jurisdiccio-

72 Corte Interamericana de Derechos Humanos, Informe Anual 2009, ob. cit., p. 3.

73 GarCía RAmíreZ, S., «El acceso de la víctima a la jurisdicción internacional sobre derechos humanos», op. cit., p. 270. 
nales internacionales no cuentan con una facultad semejante a la que poseen los tribunales nacionales para requerir el uso de la fuerza pública para hacer cumplir sus determinaciones, limitándose solo a recurrir a la instancia política representada por la Asamblea General de la OEA ${ }^{74}$. Siendo ello así, la ejecución íntegra de las sentencias emitidas por la Corte está en la voluntad del Estado, quien buenamente decidirá el momento y la forma de dar cumplimiento.

Lamentablemente conforme al último informe del 2015 emitido por la Corte Interamericana existen 172 casos en etapa de supervisión de cumplimiento de sentencias de un total de 203 casos emitidos $^{75}$ (ver Tabla 1 y Fig. 1). Esto es una muestra clara de la falta de efectividad en el cumplimiento de las decisiones de la Corte Interamericana atribuibles en primer término a los Estados y en segundo al Sistema Interamericano que no establece un órgano exclusivo de hacer el seguimiento del cumplimiento de las decisiones de la Corte Interamericana.

Tabla 1. Casos resueltos y casos en etapa de supervisión por Estado (a 31/12/2015)

\begin{tabular}{|c|c|c|c|c|c|c|c|c|c|c|c|c|c|c|c|c|c|c|c|c|c|c|c|}
\hline & \begin{tabular}{|l} 
䄈 \\
总 \\
完
\end{tabular} & 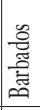 & 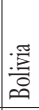 & 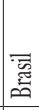 & 节 & 离 & 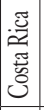 & 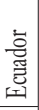 & 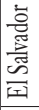 & 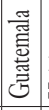 & 浔 & 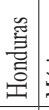 & 递 & 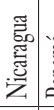 & 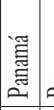 & 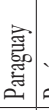 & 号 & 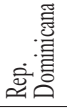 & 兽 & 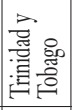 & 胥 & 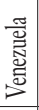 & 馬 \\
\hline Casos Resueltos & 17 & 2 & 4 & 5 & 8 & 15 & 2 & 17 & 6 & 20 & 2 & 12 & 8 & 3 & 5 & 7 & 37 & 4 & 6 & 2 & 2 & 19 & 203 \\
\hline Casos en Supervisión & 13 & 2 & 3 & 3 & 6 & 15 & 1 & 12 & 6 & 20 & 2 & 9 & 6 & 1 & 4 & 6 & 54 & 4 & 4 & 2 & 2 & 17 & 172 \\
\hline
\end{tabular}

Figura 1. Casos resueltos y casos en etapa de supervisión por Estado (a 31/12/2015)

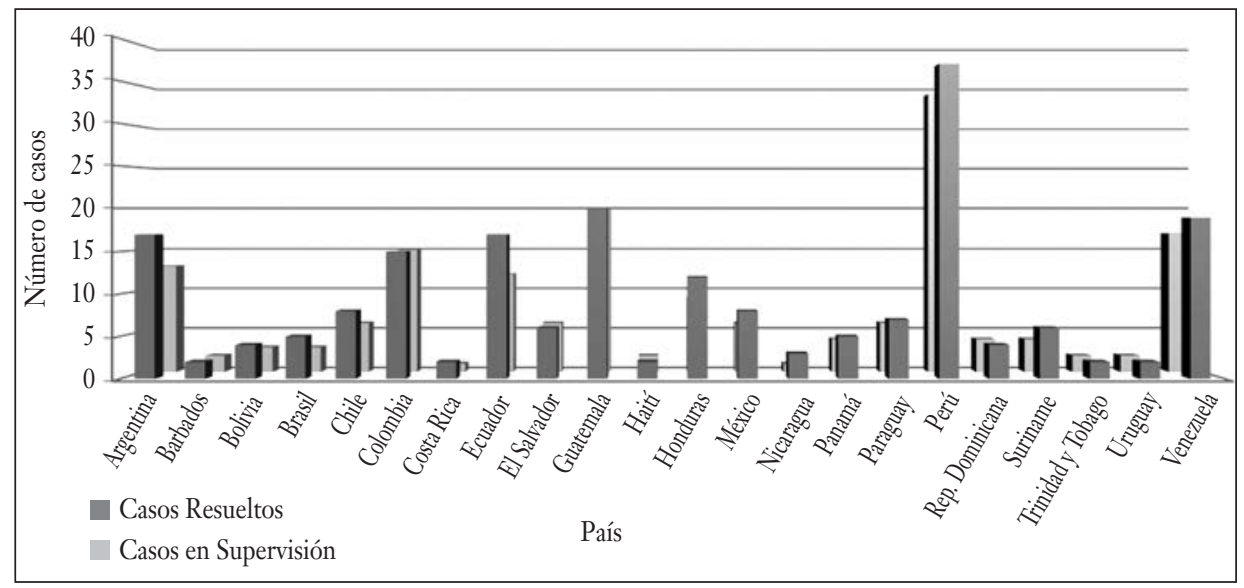

74 Ibidem.

75 Corte Interamericana de Derechos Humanos, Informe Anual 2015, op. cit., pp. 63 y 86-90. 
Así, teniendo en cuenta los datos mencionados, se concluye que la ejecución de las sentencias en general, constituye uno de los problemas del sistema interamericano y del que los Estados miembros son conscientes. Una alternativa sería la creación de un órgano encargado exclusivamente del seguimiento al cumplimiento de las sentencias emitidas por la Corte con potestad para realizar visitas a los Estados y verificar in situ dicho cumplimiento y presentar un informe que visibilice el papel de los Estados en dicho cumplimiento. La publicidad siempre será un mecanismo útil y necesario a efectos de «presionar» a los Estados en el cumplimiento de sus obligaciones internacionales en materia de derechos humanos adquiridas voluntariamente.

\section{La creación de una Corte Permanente y el fortalecimiento del Sistema interamericano}

Teniendo en cuenta lo mencionado en el epígrafe anterior adquiere mayor relevancia la creación de una Corte permanente en el Sistema Interamericano. Como ya venía señalando el ex juez de la Corte Interamericana Manuel Ventura solo con una Corte permanente «se podría hablar de que estaría funcionando en América un verdadero sistema de protección de los derechos humanos» ${ }^{7}$.

El trabajo de la Corte se encuentra apoyado por la Secretaría (un secretario general y un secretario adjunto). Solo tiene períodos de sesiones ordinarios y extraordinarios a lo largo del año. No cabe duda de la voluntad de este órgano judicial de supervisar el cumplimiento de sus decisiones, pero no resulta suficiente, más aún si vemos cuál es el mecanismo de supervisión que se sigue.

Otro aspecto a tener en cuenta para la efectividad de las ejecuciones, es la publicidad del cumplimiento o incumplimiento de las decisiones, por parte del órgano supervisor. En este sentido la Corte Interamericana a través de su página web viene emitiendo en los últimos tiempos una información cada vez más detallada sobre el statu quo de los cumplimientos e incumplimientos de sus sentencias. Es importante que la comunidad internacional sepa cuales Estados son respetuosos con sus compromisos y los que no lo son. En este aspecto

\footnotetext{
76 Ventura Robles, M., «La Corte Interamericana de Derechos Humanos: Camino hacia un tribunal permanente», Revista del Instituto Interamericano de Derechos Humanos, vol. 32-33 (2002). Edición especial sobre acceso a la justicia, p. 310.
} 
desempeñan un papel importante las distintas organizaciones, asociaciones, $\mathrm{y}$ la sociedad civil en general.

Desde luego visto lo visto, por un lado, la actitud y voluntad del Estado en el cumplimiento de las sentencias es determinante y por otro se requiere una acción enérgica por parte de la OEA ante los informes presentados anualmente por la Corte sobre el incumplimiento de sus sentencias. Sería conveniente dedicarle unos minutos en el seno de la Asamblea General al aspecto del incumplimiento de sentencias presentado en el informe. Por otro lado, además, la existencia de una Corte permanente incidiría mucho en la efectividad del sistema en general. Podría conocer de muchos más casos y en tiempo más breve.

\section{Las denuncias de los Estados a la CADH y el debilitamiento del Sistema}

La CADH así como reconoce las Reservas, las Enmienda y Protocolos a la Convención Americana, también permite la denuncia a la misma al señalar en el art. 78 que: «Los Estados Partes podrán denunciar esta Convención después de la expiración de un plazo de cinco años a partir de la fecha de entrada en vigor de la misma y mediante un preaviso de un año, notificando al Secretario General de la Organización, quien debe informar a las otras partes». «Dicha denuncia no tendrá por efecto desligar al Estado parte interesado de las obligaciones contenidas en esta Convención en lo que concierne a todo hecho que, pudiendo constituir una violación de esas obligaciones, haya sido cumplido por él anteriormente a la fecha en la cual la denuncia produce efecto».

Sin duda esto significa que cualquier Estado cuando lo considere necesario puede denunciar a la Convención y para ello no requiere cumplir ningún requisito especial más que un preaviso de un año notificando al Secretario General de la OEA. Afortunadamente los Estados que han asumido seriamente proteger los derechos humanos a las personas que se encuentran bajo su jurisdicción al ratificar la Convención y asumir la Competencia contenciosa de la Corte son en su mayoría coherentes con dicho compromiso. No obstante hay Estados que han planteado la denuncia a la Convención con éxito, alguno que planteó el retiro de la Corte sin éxito y otro Estado que aún no sabemos qué hará dado que su Tribunal Constitucional ha declarado la inconstitucionalidad del instrumento de aceptación de la competencia de la Corte. Estas situaciones debilitan el buen funcionamiento del Sistema Interamericano y especialmente de la Corte Interamericana. 
La primera denuncia la realizó Trinidad y Tobago bajo el argumento de incompatibilidad de la Convención Americana y su derecho interno el 26 de mayo de 1998. La misma que surtió efecto un año después. Previamente a ello, como señalamos supra había incumplido las medidas provisionales adoptadas por la Corte para salvaguardar y asegurar los derechos de los condenados a pena de muerte, sin ningún tipo de consecuencias. No hubo pronunciamiento al respecto por parte de la OEA ni respaldando la decisión de la Corte ni condenando la actitud del Estado.

Luego Perú, durante el gobierno de Alberto Fujimori, como consecuencia de las sentencias emitidas por la Corte Interamericana por la violación de los derechos humanos contra este país y otros casos que se encontraban ante la Comisión ${ }^{77}$ decidió plantear su retiro a la competencia de la Corte el 9 de julio de 1999 poniendo en conocimiento de la Secretaría General de la OEA. Petición que no surtió efectos por cuanto la Corte haciendo uso del principio de la competencia de la competencia manifestó la invalidez del retiro dado que Perú no podía plantear el retiro de la Corte por cuanto no existe en la Convención ninguna norma que faculte a los Estados partes a retirar su declaración de aceptación de la competencia obligatoria de la Corte. Así, la única posibilidad de que un Estado pueda desvincularse del sometimiento a la competencia contenciosa de la Corte conforme a la $\mathrm{CADH}$ es la denuncia como un todo. Perú no podía por un lado mantenerse vinculado a la Convención y por otro renunciar a la competencia de la Corte interamericana, órgano creado por la Convención. Sin embargo, su retiro hubiera sido procedente si Perú denunciaba a la CADH como un todo, y esto incluía a la Corte.

El último Estado en retirarse de la Convención es Venezuela. Planteó su retiro también como consecuencia de las sentencias emitidas por la Corte por la violación de los derechos humanos en dicho país, el 10 de septiembre de 2012, retiro que se hizo efectivo el 10 de septiembre de 2013. El argumento de Venezuela fue la vulneración de la soberanía del Estado. Manifestó en el documento de denuncia «que en los últimos años la práctica de los órganos regidos por el Pacto de San José, tanto la Comisión Interamericana de Derechos Humanos como la Corte Interamericana de Derechos Humanos, se han alejado de los sagrados principios que están llamados a proteger, convirtiéndose en un arma política arrojadiza destinada a minar la

77 Ya la Corte había emitido sentencia en el caso Loayza Tamayo y Castillo Petruzzi, y en la Comisión se encontraban en trámite el caso Tribunal Constitucional e Ivcher Bronstein. 
estabilidad de determinados gobiernos, y especialmente al de nuestro país, adoptando una línea de acción injerencista en los asuntos internos de nuestro gobierno, vulnerando y desconociendo principios básicos y esenciales ampliamente consagrados en el derecho internacional, como lo son el principio de respeto de la soberanía de los Estados y el de autodeterminación de los pueblos $(\ldots) \gg^{78}$.

De esta forma estos dos Estados se apartan de la Convención y de la Corte Americana y dejan a las personas que se encuentran bajo su jurisdicción sin la protección internacional, de ser necesario. No obstante es de señalar que tanto la Corte como la Comisión seguirán conociendo de casos anteriores a la denuncia. Asimismo, la Comisión interamericana tendrá competencia para seguir protegiendo derechos y garantía como miembro de la OEA, en mérito a la Declaración Americana de los Derechos y Deberes del Hombre y la Carta de la OEA.

Otro caso a destacar es el de República Dominicana, aunque no se trata de una denuncia a la Convención, es importante mencionarlo debido a las consecuencias que pueda traer la decisión del Tribunal Constitucional de dicho país. República Dominicana ratificó la CADH el 19 de abril de 1978, más tarde el 19 de febrero de 1999 durante el gobierno de Leonel Fernández se procedió a la aceptación de la competencia contenciosa de la Corte. El «problema» radica en la aceptación de la competencia contenciosa de la Corte por cuanto en palabras de los ciudadanos que interpusieron en el 2005 una acción de inconstitucionalidad contra dicho instrumento, éste no contó con el procedimiento constitucional establecido, es decir, no ha sido ratificado por el Congreso y solo fue un acto unilateral del gobierno por cuanto carece de validez. El Tribunal Constitucional en el 2014 se pronunció declarando la inconstitucionalidad del documento de aceptación de la competencia de la Corte. Esto significa que este país estaría vinculado por la $\mathrm{CADH}$ pero no por la Corte como lo ha dicho este órgano judicial interno. Es de señalar que la Corte días antes del planteamiento de la acción en el derecho interno también había emitido una sentencia condenando a este país por la violación de los derechos humanos.

La Corte ya se había pronunciado en años anteriores contra este Estado sin que existiera objeción alguna en contra de la competencia contenciosa de

78 El documento completo de la denuncia puede verse en <www.oas.org/dil/esp/Nota_Republica_Bolivariana_de_Venezuela_al_SG_OEA.PDF > [última visita: 02-2016]. 
la Corte ${ }^{79}$. Es más, hubo una jueza de este país, Radhys Abreu Blondet, que desempeñó el cargo desde el 2007 al 2012, signo evidente de la aceptación por parte del Estado de la competencia de la Corte. Desde luego el argumento bajo el cual pretende desligarse de la competencia de la corte no tiene sentido y es oportunista. Teniendo en cuenta el caso de Perú, entendemos que la única vía para que República Dominicana se retire de la Corte es plantear la denuncia a la Convención Americana como un todo.

\section{REFLEXIONES FINALES}

Hace sesenta y ocho años que se adoptó el primer instrumento de derechos humanos en el sistema interamericano, hace treinta y ocho años que viene funcionando la Corte Interamericana de Derechos Humanos y el balance no puede ser sino positivo. Sus sentencias y sus opiniones consultivas han sido innovadoras y vienen contribuyendo en un mejor reconocimiento de los derechos humanos en la región. Hubo modificatorias al Reglamento de la Corte con un único objetivo, posibilitar el acceso al ámbito internacional de protección de los derechos humanos en dicha parte del mundo a personas con menos posibilidades económicas. Los Estados de la región en su gran mayoría contribuyen en el reconocimiento de los derechos humanos y en darle estabilidad al sistema. Aunque lo ideal sería la existencia de un mayor compromiso por parte de los Estados que forman parte de la OEA con el Sistema Interamericano como sucede en el Consejo de Europa.

No obstante, no podemos dejar de lado otros aspectos que perjudican o pueden llegar a debilitar el sistema, es el caso del incumplimiento de las sentencias por parte de los Estados y la falta de un órgano creado ad hoc para la supervisión de dicho cumplimiento. Sin el cumplimiento de sentencias en su totalidad no podemos hablar de un sistema efectivo en la protección de los derechos humanos. Está en manos del Estado, no solo incorporar en su derecho

79 Corte Interamericana de Derechos Humanos, caso Corte IDH. Caso de las Niñas Yean y Bosico c. República Dominicana. Sentencia de 8 de septiembre de 2005; Corte IDH. Caso González Medina y familiares c. República Dominicana. Excepciones Preliminares, Fondo, Reparaciones y Costas. Sentencia de 27 de febrero de 2012; Corte IDH. Caso Nadege Dorzema y otros c. República Dominicana. Fondo Reparaciones y Costas. Sentencia de 24 de octubre de 2012; y Corte IDH. Caso de personas dominicanas y haitianas expulsadas c. República Dominicana. Excepciones Preliminares, Fondo, Reparaciones y Costas. Sentencia de 28 de agosto de 2014. 
interno los derechos reconocidos en el sistema interamericano sino también asegurar el cumplimiento efectivo de las decisiones de la Corte conforme a los compromisos adquiridos voluntariamente al ratificar la Convención y asumir la competencia contenciosa de la Corte. Los Estados deben ser lo suficientemente responsables para responder a sus obligaciones internacionales y ante sus irresponsabilidades no utilizar medidas como la denuncia para «huir» del cumplimiento de tales obligaciones. Por otro la OEA debe plantearse en fortalecer el sistema a través de la creación de una Corte permanente y que económicamente dependa de los Estados Partes y no de la voluntad de otros Estados ajenos al sistema. Solo así podremos hablar de protección real y efectiva de los derechos humanos en la región.

De este modo el desarrollo de los derechos humanos se ha dado a través de la sus dos órganos. Cada uno de ellos se ha ido pronunciando sobre la violación de los derechos humanos en la región americana dependiendo del compromiso de los Estados frente al sistema, es decir, teniendo en cuenta la firma de la CADH o el haber asumido la competencia contenciosa de la Corte.

Se trata de un sistema que a pesar de los inconvenientes y dificultades ha venido y viene protegiendo los derechos humanos. Pero la efectividad del sistema pasa fundamentalmente por la responsabilidad, compromiso y voluntad de los Estados en el reconocimiento y protección de los derechos humanos, y en su caso, en el cumplimiento en su totalidad de las decisiones de la Corte Interamericana. Lo ideal, sería, activar lo menos posible las instancias internacionales. Siendo ello así, en materia de derechos humanos, el Estado es el actor principal en garantizar la efectividad de éstos. Está en sus manos proteger los derechos humanos de manera efectiva de quienes se encuentran bajo su jurisdicción. 